\title{
The study of quality attributes of parboiled rice during steaming process with revolved sieve
}

\author{
Thatchapol Chungcharoen ${ }^{1, *}$, Naruebodee Srisang ${ }^{1}$, and Siriwan Srisang ${ }^{1}$ \\ ${ }^{1}$ Engineering Department, King Mongkut's Institute of Technology Ladkrabang, Prince of Chumphon Campus, Chumphon, Thailand
}

\begin{abstract}
The steaming process with revolved sieve was studied as a function of steaming time and revolution velocity. The quality of parboiled rice in terms of thermal property, head rice yield and color was investigated and compared to the conventional steaming process such as fixed sieve. The experimental results showed that the steaming process with revolved sieve had advantage over the steaming process with fixed sieve. It led to a steamed sample with higher DG higher head rice yield and lower whiteness value. The required steaming time for a regularity quality by a steaming process with revolved sieve was also shorter. Moreover, the steaming time affected the qualities of parboiled rice. The long steaming time provided the higher DG and head rice yield and lower whiteness value of parboiled rice. Considering revolution velocity, it was found that the revolution velocity did not affect the qualities of parboiled rice. However, the revolution velocity of $5 \mathrm{rpm}$ with steaming time of $5 \mathrm{~min}$ provided the difference of quality at each layer.
\end{abstract}

\section{Introduction}

Parboiled rice is the staple food in South Asian countries and it has a market share of $20-50 \%$ of world rice production [1]. Nowadays, parboiled rice is one of healthy foods which have increasingly been interested, especially in health conscious people because of the high nutrient value. Normally, rice parboiling process consists of three different operations, namely soaking, steaming and drying. First, rice was steeped in water at $70^{\circ} \mathrm{C}$ for 5 $\mathrm{hr}$ [2]. The main objective of rice soaking is to achieve uniform water absorption [3] and to provide the enough moisture content of rice about $44-45 \%$ (d.b.) [4] for the establishment of starch gelatinization in steaming process. Secondly, the soaked rice was steamed to achieve partial or complete gelatinization [5]. Finally, rice was dried to save the moisture content of $16 \%$ (d.b.) [6] for storage and milling.

Steaming is important process to provide the high quality of parboiled rice, especially head rice yield because this is the main process to create the gelatinization. This process, currently, is performed by the steaming with fixed sieve. The soaked paddy was placed on the fixed sieve and then, the saturated steam was blown throughout the paddy bed. This caused the incomplete gelatinization because the saturated steam was not completely contacted the paddy bed [7], resulting in the lower head rice yield. Moreover, the color of parboiled rice was not similar for all samples. To alleviate this problem, it should limit the amounts of soaked paddy which was placed on the sieve or increase the steaming temperature and steaming time to achieve complete gelatinization. However, their solving consumed more energy to produce the parboiled rice, leading to increase energy cost. One of possible solving which is the better way can be done by using the steaming with revolved sieve. It provided the moveable soaked paddy during steaming, leading to completely contact with the saturated steam, resulting in the easily complete gelatinization.

Therefore, the objectives of this work were to design and to create the steaming with revolved sieve and also to investigate the effects of revolution velocity and steaming time on the qualities of parboiled rice. The assessment of quality attributes of parboiled rice during steaming process was considered in terms of thermal property, head rice yield and color. They were compared with those of the steaming with fixed sieve.

\section{Materials and methods}

\subsection{Materials}

Suphanburi 1 paddy obtained from the Rice department, Suphanburi, Thailand was used as the sample rice in this study. Its moisture content and amylose content were about $12-13 \%$ dry basis (d.b.) and 25-30\%, respectively. The paddy had already stored for a month prior to an experiment.

\subsection{Preparation of sample}

The $2.5 \mathrm{~kg}$ of paddy was steeped in controlled temperature water at $70^{\circ} \mathrm{C}$ for 5 hours. The hot water was then discarded and the paddy was stored in the

\footnotetext{
* Corresponding author: Thatchapol.ch@kmitl.ac.th
} 
plastic box for 1 hour prior to steam. The soaked paddy was then steamed by a steaming process with revolved sieve shown in Fig. 1. The steaming system was comprised of stainless steel cylindrical revolved sieve of $30 \mathrm{~cm}$ diameter and $30 \mathrm{~cm}$ length, a pulley driven by a 1 HP motor, and a boiler with a capacity of $500 \mathrm{~kg} / \mathrm{h}$. The boiler produced the saturated steam at $106 \mathrm{kPa}$ and flowed through steaming chamber. For stainless steel cylindrical revolved sieve, it had 4 fins inside the sieve and 2 holes on the side wall for separating sample layer by flat plate (shown in Fig. 2a). The steaming conditions were set at steaming times of 5,10 and $15 \mathrm{~min}$, revolution velocities of 5,10 , and $15 \mathrm{rpm}$, a bed height was fixed at $8 \mathrm{~cm}$ and a steaming temperature was set at $103^{\circ} \mathrm{C}$. For steaming process with fixed sieve, the soaked paddy were taken to steam at the above steaming conditions but the sieve was not revolved. After finishing the steaming, the steam was stopped and suddenly blown out by bottom valve to avoid the overheating and then the revolved sieve was taken out. The steamed paddy was divided into three layers such as top, middle and bottom (shown in Fig. 2b) by flat plate. In the last step, each layer was taken out for quality determination. The quality of sample obtained from the steaming process with revolved sieve was also compared with that of sample obtained from the steaming process with fixed sieve.

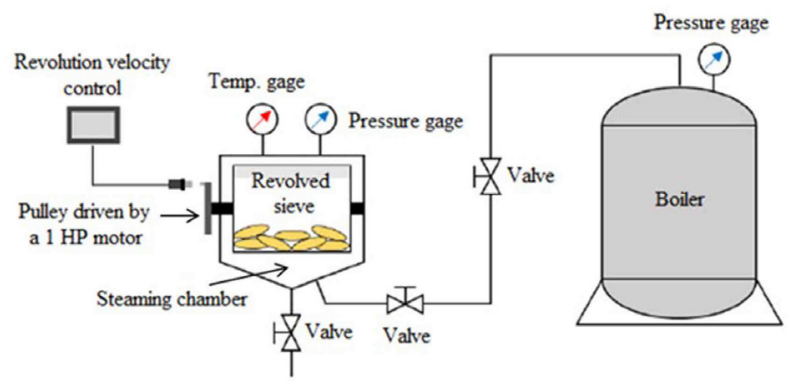

Fig. 1. Schematic diagram of steaming process with revolved sieve

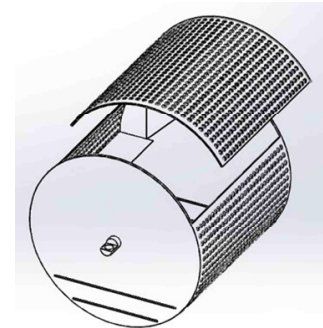

a) Sieve

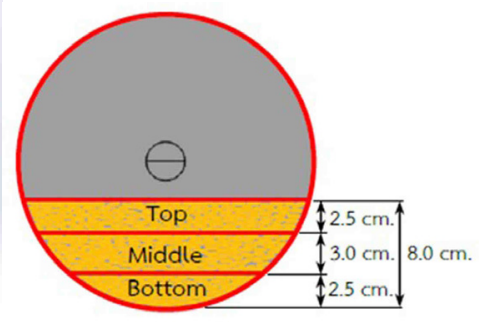

b) Layer of steamed paddy
Fig. 2. Details of cylindrical revolved sieve

\subsection{Qualities determination}

The degree of starch gelatinization (DG) was investigated using a differential scanning calorimeter (DSC; Perkin Elmer Co. Ltd., model DSC-7, Norwalk, USA). The head rice yield (HRY) was defined as a percentage of unbroken parboiled rice mass to paddy mass before milling. A digital whiteness meter (New Agronic, model W-600, Taiwan) was used for measuring the color of sample.

\section{Results and discussion}

\subsection{Thermal property}

Table 1 shows the enthalpy $(\Delta \mathrm{H})$ and degree of starch gelatinization (DG) of the parboiled rice steamed by fixed sieve and revolved sieve. The $\Delta \mathrm{H}$ required for the complete gelatinization of reference rice was $9.28 \mathrm{~J} / \mathrm{g}$. When the rice sample was soaked and steamed by fixed sieve and revolved sieve, the $\Delta \mathrm{H}$ decreased as compared to the reference rice, implying the occurrence of starch gelatinization [8]. The lower $\Delta \mathrm{H}$ values for the treated samples were due to the modification of starch granule. During steaming, some starch granules lost their shape and were fused together. The $\Delta \mathrm{H}$ required to melt starch was therefore lower. In the case of steaming process with revolved sieve at steaming time of $15 \mathrm{~min}$, the $\Delta \mathrm{H}$ values were 0 at every revolution velocity. This indicated that the destruction of starch granule was completed. The $\Delta \mathrm{H}$ required to melt starch could not be found in these conditions. For steaming with fixed sieve, the DG at each layer was different when steaming at steaming time of 5 or $10 \mathrm{~min}$. The DGs at middle layer were clearly lower than that at top and bottom layer at the same steaming time. This indicated that the saturated steam was not completely contacted the sample bed. When increasing the steaming time to $15 \mathrm{~min}$, the DG was not different at each layer. From these data, it implied that the steaming time of $15 \mathrm{~min}$ was enough to obtain the complete of contact between sample and steam during steaming process with fixed sieve. However, it did not provide the complete gelatinization. For steaming with revolved sieve, the difference of DG at each layer was found specifically at steaming time of $5 \mathrm{~min}$ and revolution velocity of $5 \mathrm{rpm}$. When comparing between fixed sieve and revolved sieve, it can be seen that the DG was quite different although they were steamed at the same steaming time. The DG of sample with revolved sieve was relatively higher than that of sample with fixed sieve. Moreover, the gelatinization of rice starch was completed in the steaming process with revolved sieve at steaming time of $15 \mathrm{~min}$. From these data, it implied that the steaming time of $10 \mathrm{~min}$ was enough to obtain the complete of contact between paddy and steam during steaming process with revolved sieve at every revolution velocity. In addition, The DG increased with an increase in steaming time while the revolution velocity did not affect the DG.

\subsection{Head rice yield}

Fig. 3 shows the head rice yield percentage of parboiled rice during steaming process with fixed sieve at steaming times of 5, 10 and $15 \mathrm{~min}$. It was found that the steaming times of 5 and 10 min provided the different head rice yield percentage at each layer as shown in FIGURE 3 (a, 
b). The head rice yield percentages at middle layer were about $69.57 \%$ and $71.28 \%$ for steaming times of 5 and 10 min, respectively, while the head rice yield percentages at top and bottom layer were approximately 71.12 and $70.94 \%$ for steaming time of $5 \mathrm{~min}$ and 72.07 and $71.91 \%$ for steaming time of $10 \mathrm{~min}$, respectively. These results corresponded to the thermal property result, showing the low DG at middle layer. However, the head rice yield percentage of each layer at steaming time of 15 min was not different.

Table 1. The degree of starch gelatinization (DG) of parboiled rice at various steaming conditions.

\begin{tabular}{|c|c|c|c|c|c|}
\hline Sample & $\begin{array}{l}\text { Steaming } \\
\text { time (Min) }\end{array}$ & $\begin{array}{c}\text { Revolution } \\
\text { velocity (RPM) }\end{array}$ & Layer & $\Delta \mathrm{H}(\mathrm{J} / \mathrm{g})$ & DG $(\%)$ \\
\hline Reference rice & - & - & - & $9.28 \pm 0.01^{\mathrm{a}}$ & - \\
\hline \multirow{9}{*}{$\begin{array}{l}\text { Parboiled rice } \\
\text { (Fixed sieve) }\end{array}$} & \multirow{3}{*}{5} & - & Top & $3.09 \pm 0.02^{\mathrm{f}}$ & $66.69 \pm 0.20^{\mathrm{fg}}$ \\
\hline & & - & Middle & $3.94 \pm 0.02^{\mathrm{b}}$ & $57.60 \pm 0.14^{\mathrm{i}}$ \\
\hline & & - & Bottom & $3.36 \pm 0.07^{\mathrm{c}}$ & $63.75 \pm 0.68^{\mathrm{h}}$ \\
\hline & \multirow{3}{*}{10} & - & Top & $1.98 \pm 0.05^{\mathrm{k}}$ & $78.63 \pm 0.50^{\mathrm{c}}$ \\
\hline & & - & Middle & $2.33 \pm 0.05^{\mathrm{i}}$ & $74.94 \pm 0.53^{\mathrm{d}}$ \\
\hline & & - & Bottom & $2.13 \pm 0.05^{\mathrm{j}}$ & $77.05 \pm 0.53^{\mathrm{c}}$ \\
\hline & \multirow{3}{*}{15} & - & Top & $0.18 \pm 0.08^{\mathrm{m}}$ & $98.05 \pm 0.88^{\mathrm{a}}$ \\
\hline & & - & Middle & $0.19 \pm 0.03^{\mathrm{m}}$ & $98.01 \pm 0.28^{\mathrm{a}}$ \\
\hline & & - & Bottom & $0.18 \pm 0.01^{\mathrm{m}}$ & $98.10 \pm 0.08^{\mathrm{a}}$ \\
\hline \multirow{27}{*}{$\begin{array}{c}\text { Parboiled rice } \\
\text { (Revolved } \\
\text { sieve ) }\end{array}$} & \multirow{9}{*}{5} & \multirow{3}{*}{5} & Top & $3.2 \pm 0.01^{\mathrm{de}}$ & $65.56 \pm 0.08^{\mathrm{gh}}$ \\
\hline & & & Middle & $2.96 \pm 0.02^{\mathrm{g}}$ & $68.06 \pm 0.18^{\mathrm{ef}}$ \\
\hline & & & Bottom & $2.86 \pm 0.01^{\mathrm{h}}$ & $69.15 \pm 0.07^{\mathrm{e}}$ \\
\hline & & \multirow{3}{*}{10} & Top & $3.19 \pm 0.04^{\mathrm{de}}$ & $65.64 \pm 0.40^{\mathrm{gh}}$ \\
\hline & & & Middle & $3.18 \pm 0.01^{\mathrm{e}}$ & $65.69 \pm 0.13^{\mathrm{gh}}$ \\
\hline & & & Bottom & $3.21 \pm 0.03^{\mathrm{de}}$ & $65.44 \pm 0.34^{\mathrm{gh}}$ \\
\hline & & \multirow{3}{*}{15} & Top & $3.22 \pm 0.00^{\mathrm{de}}$ & $65.32 \pm 0.03^{\mathrm{gh}}$ \\
\hline & & & Middle & $3.25 \pm 0.05^{\mathrm{d}}$ & $65.02 \pm 0.50^{\mathrm{gh}}$ \\
\hline & & & Bottom & $3.19 \pm 0.01^{\mathrm{de}}$ & $65.54 \pm 0.10^{\mathrm{gh}}$ \\
\hline & \multirow{9}{*}{10} & \multirow{3}{*}{5} & Top & $0.701 \pm 0.01^{1}$ & $92.45 \pm 0.10^{\mathrm{b}}$ \\
\hline & & & Middle & $0.74 \pm 0.02^{1}$ & $92.08 \pm 0.17^{\mathrm{b}}$ \\
\hline & & & Bottom & $0.72 \pm 0.00^{1}$ & $92.29 \pm 0.03^{\mathrm{b}}$ \\
\hline & & \multirow{3}{*}{10} & Top & $0.71 \pm 0.01^{1}$ & $92.34 \pm 0.10^{b}$ \\
\hline & & & Middle & $0.72 \pm 0.02^{1}$ & $92.23 \pm 0.16^{\mathrm{b}}$ \\
\hline & & & Bottom & $0.73 \pm 0.01^{1}$ & $92.18 \pm 0.12^{b}$ \\
\hline & & \multirow{3}{*}{15} & Top & $0.71 \pm 0.01^{1}$ & $92.31 \pm 0.08^{\mathrm{b}}$ \\
\hline & & & Middle & $0.73 \pm 0.03^{1}$ & $92.17 \pm 0.27^{\mathrm{b}}$ \\
\hline & & & Bottom & $0.71 \pm 0.01^{1}$ & $92.36 \pm 0.10^{\mathrm{b}}$ \\
\hline & \multirow{9}{*}{15} & \multirow{3}{*}{5} & Top & 0 & 100.00 \\
\hline & & & Middle & 0 & 100.00 \\
\hline & & & Bottom & 0 & 100.00 \\
\hline & & \multirow{3}{*}{10} & Top & 0 & 100.00 \\
\hline & & & Middle & 0 & 100.00 \\
\hline & & & Bottom & 0 & 100.00 \\
\hline & & \multirow{3}{*}{15} & Top & 0 & 100.00 \\
\hline & & & Middle & 0 & 100.00 \\
\hline & & & Bottom & 0 & 100.00 \\
\hline
\end{tabular}

a-m Means with different superscripts in the same column are significantly different $(\mathrm{p}<0.05)$

Fig. 4 shows the effect of revolution velocity on the head rice yield percentage of parboiled rice during steaming process with revolved sieve at steaming time of $5 \mathrm{~min}$. It was found that the revolution velocity affected the head rice yield percentage of parboiled rice. The difference of head rice yield percentage at each layer occurred when the sieve was revolved at $5 \mathrm{rpm}$. The head rice yield percentage at middle layer was also lower than that at top and bottom layer as shown in Fig 4(a). When the revolution velocity was increased to 10 or $15 \mathrm{rpm}$, the head rice yield percentage at each layer was not different. Moreover, it was found that the revolution velocity did not affect the head rice yield percentage of parboiled rice at each layer when increasing steaming time to 10 or $15 \mathrm{~min}$ (data not shown). It confirmed that the saturated steam was completely contacted the sample bed as already mentioned above. Furthermore, the head rice yield percentage increased with an increase of steaming time.

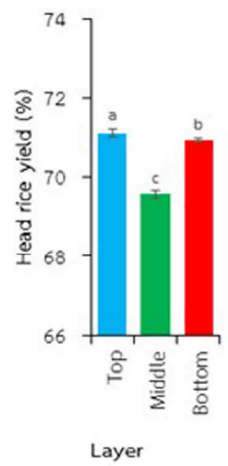

(a)

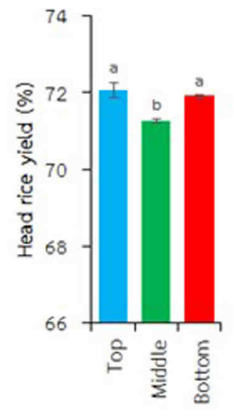

Layer

(b)

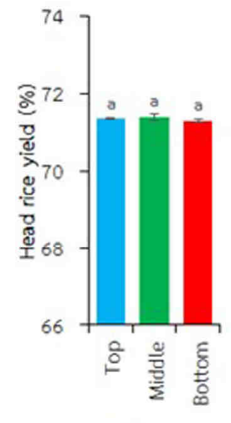

Layer

(c)
Fig. 3. The percentage of head rice yield of parboiled rice during steaming process with fixed sieve at (a) steaming time of $5 \mathrm{~min}$, (b) steaming time of $10 \mathrm{~min}$ and (c) steaming time of $15 \mathrm{~min}$.

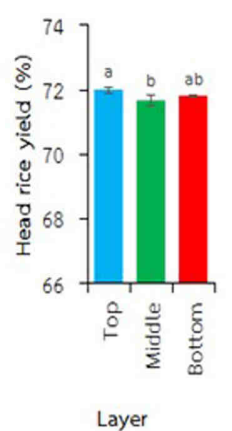

(a)

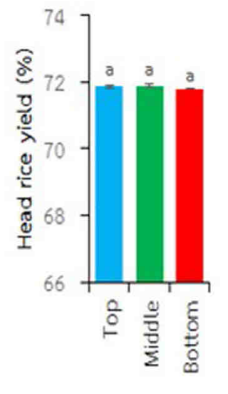

Layer

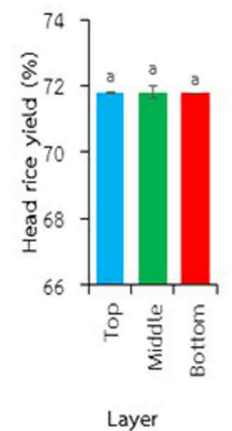

(c)
Fig. 4. The percentage of head rice yield of parboiled rice during steaming process with revolved sieve at steaming time of $5 \mathrm{~min}$; (a) revolution velocity of $5 \mathrm{rpm}$, (b) revolution velocity of $10 \mathrm{rpm}$ and (c) revolution velocity of $15 \mathrm{rpm}$

\subsection{Color}

The whiteness values of parboiled rice during steaming process with fixed sieve at various steaming times are presented in Fig. 5. The whiteness value at each layer was different when steaming at steaming time of 5 or 10 min. This result was expected since the DG and the head rice yield percentage at each layer was also different during these steaming times. The whiteness value of sample with middle layer at steaming time of 5 or 10 
min was higher than that with top and bottom layer at the same steaming time (shown in Fig. $5(\mathrm{a}, \mathrm{b})$ ). Moreover, it was found that the color of parboiled rice changed in a way that the whiteness value was decreased with increasing steaming time. This is because the long steaming time could produce more Maillard browning reactions [9].

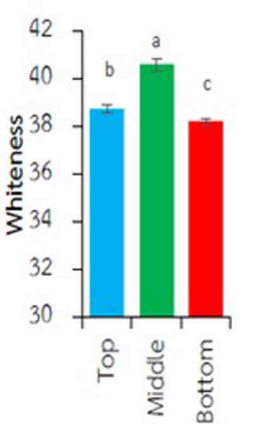

Layer

(a)

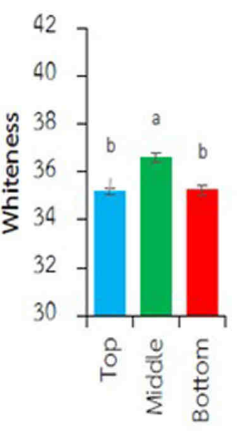

Layer

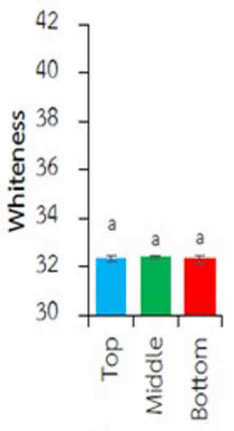

Layer
Fig. 5. The whiteness value of parboiled rice during steaming process with fixed sieve at (a) steaming time of $5 \mathrm{~min}$, (b) steaming time of $10 \mathrm{~min}$ and (c) steaming time of $15 \mathrm{~min}$

Fig. 6 shows the effect of revolution velocity on the whiteness value of parboiled rice during steaming process with revolved sieve at steaming time of $5 \mathrm{~min}$. It was found that the difference of whiteness value at each layer did not take place during revolution velocities of 10 and $15 \mathrm{rpm}$ the when steaming by revolved sieve at steaming time of 5 min (shown in Fig. 6 (b, c) as same as the results of DG and head rice yield percentage. As the steaming time was increased to 10 or $15 \mathrm{~min}$, the whiteness value at each layer was similar. It was about 32 and $35 \%$ for steaming time of $10 \mathrm{~min}$ and $15 \mathrm{~min}$, respectively (data not shown). It confirmed that the saturated steam was completely contacted the sample bed at these steaming times.

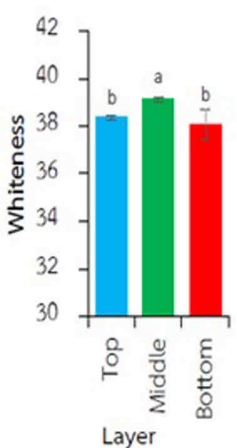

(a)

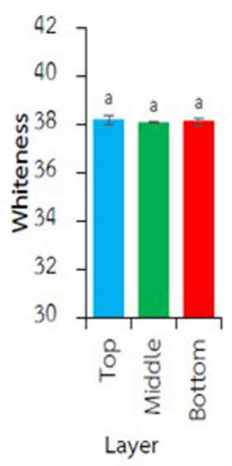

(b)

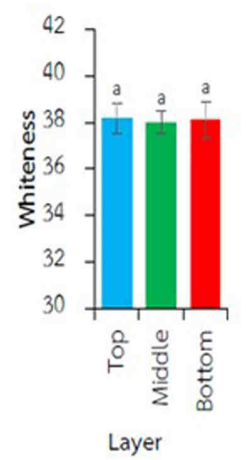

(c)
Fig. 6. The whiteness value of parboiled rice during process with revolved sieve at steaming time of $5 \mathrm{~min}$; (a) revolution velocity of $5 \mathrm{rpm}$, (b) revolution velocity of $10 \mathrm{rpm}$ and (c) revolution velocity of $15 \mathrm{rpm}$

\section{Conclusions}

The steaming process with revolved sieve could reduce the steaming time for a regularity quality. Its steaming time was 10 min while the time with regularity quality by steaming process with fixed bed was $15 \mathrm{~min}$. The DG and the head rice yield were higher in the steaming process with revolved sieve than in the steaming process with fixed bed. Nevertheless, the whiteness value in the steaming process with fixed bed was higher. The qualities of parboiled rice in both steaming process changed with steaming time. The DG and the head rice yield were increased with increasing steaming time while the whiteness value was decreased. However, the revolution velocity did not affect the qualities of parboiled rice.

\section{Acknowledgments}

The authors express the sincere appreciation to the King Mongkut's Institute of Technology Ladkrabang (KREF046011) for supporting the study financially.

\section{References}

1. N.H. Choudhury, IRRI, 47-54 (1991)

2. S. Pruengam, S. Soponronnarit, S. Prachayawarakorn, S. Devahastin, Drying Technol. 32, 1949-1955 (2014)

3. J.E. Wimberly, International Rice Research Institute, 101-116 (1983)

4. C. Taechapairoj, S. Prachayawarakorn, S. Soponronnarit, J. Food Eng. 76, 411-419 (2006)

5. H. Dutta, C.L. Mahanta, Food Res. Int., 655-663 (2012).

6. S. Soponronnarit, S. Prachayawarakorn, Dry. Technol., 1667-1686 (1994).

7. T. Chungcharoen, S. Prachayawarakorn, S. Soponronnarit, G. Srzednicki, AIP Conference Proceeding, (International Symposium on Engineering, Energy and Environment, November 17-20, Bangkok, 2013).

8. S. Tirawanichakul, S. Prachayawarakorn, W. Varanyanond, P. Tungtrakul, S. Soponronnarit, Dry. Technol., 1731-1754 (2004).

9. L. Lamberts, I. Rombouts, K. Brijs, K. Gebruers, J. A. Delcour, Food Chem., 916-922 (2008). 